\title{
Metal-Organic-Frameworks for Cultural Heritage preservation: the case of acetic acid removal
}

Kevin Dedecker, ${ }^{a, b}$ Renjith S. Pillai, ${ }^{c}$ Farid Nouar, ${ }^{d}$ João Pires, ${ }^{e}$ Nathalie Steunou, ${ }^{a}$ Eddy Dumas, ${ }^{a}$ Guillaume Maurin, ${ }^{* c}$ Christian Serre ${ }^{* d}$ and Moisés L. Pinto*f

a. Institut Lavoisier de Versailles, UMR CNRS 8180, Université de Versailles St-Quentin-en-Yvelines, Université Paris-Saclay, 78035 Versailles Cedex, France.

b. Centre de Recherche sur la Conservation, USR3224: CNRS-MNHN-MCC, Sorbonne Universités 36 rue GeoffroySaint-Hilaire, 75005 Paris Cedex, France.

c. Institut Charles Gerhardt Montpellier, UMR-5253, Université de Montpellier, ENSCM, CNRS, 34095 Montpellier cedex 05, France.E-mail: gmaurin@univ-montp2.fr

d. Institut des Matériaux Poreux de Paris (IMAP), FRE CNRS 2000, Ecole Normale Supérieure de Paris, Ecole Supérieure de Physique et de Chimie Industrielles de Paris, PSL Research University, 75005 Paris, France. E-mail: christian.serre@espci.fr

e. COB e CQE, Faculdade de Ciências, Universidade de Lisboa, 1749-016 Lisboa, Portugal.

f. CERENA, Departamento de Engenharia Química, Instituto Superior Técnico, Universidade de Lisboa, 1049-001

Lisboa,Portugal.E-mail:moises.pinto@tecnico.ulisboa.pt

\section{Abstract}

The removal of low concentrations of acetic acid from indoor air at museums poses serious preservation problems that the current adsorbents cannot easily address owing to their poor affinity for acetic acid and/or their low adsorption selectivity versus water. In this context, a series of topical water-stable metalorganic frameworks (MOFs) with different pore sizes, topologies, hydrophobic characters, and functional groups was explored through a joint experimentalcomputational exploration. We demonstrate how a subtle combination of sufficient hydrophobicity and optimized host-guest interactions allows one to overcome the challenge of capturing traces of this very polar volatile organic compound in the presence of humidity. The optimal capture of acetic acid was accomplished with MOFs that do not show polar groups in the inorganic node or have lipophilic but polar (e.g., perfluoro) groups functionalized to the organic linkers, that is, the best candidates from the list of explored MOFs are MIL-140B and UiO-66-2 $\mathrm{CF}_{3}$. These two MOFs present the appropriate pore size to favor a high degree of confinement, together with organic spacers that allow an enhancement of the van der Waals interactions with the acetic acid. We establish in this work that MOFs can be a viable solution to this highly challenging problem in cultural heritage protection, which is a new field of application for this type of hybrid materials. 


\section{Introduction}

Cultural heritage plays a central role in modern societies because it is regarded not only as a cultural but also as an economical asset. Its long-term protection is currently a highly demanding goal. In this context, it is commonly accepted that acetic acid $\left(\mathrm{CH}_{3}-\mathrm{CO}_{2} \mathrm{H}\right)$ is a major pollutant inside museums.(1) Cultural heritage conservation at museums and historical buildings requires a strict control of its concentration in indoor air and inside showcases.(2-10) This volatile organic compound (VOC) causes reduction in the degree of polymerization of cellulose in paper, corrosion of lead-containing alloys and other metals, and degradation of calcareous materials (stones, ceramics).(7,8,11,12) Acetic acid can be readily formed from the degradation of woods $(13)$ and, thus, its complete elimination is difficult, if not impossible, and a regular monitoring of its concentration in air is being proposed. $(8,14,15)$ A very low upper-limit concentration of acetic acid of 400 and $40 \mathrm{ppb}$ for a 1 and 100 year preservation target, respectively, for museums, galleries, libraries, and archival collections is recommended.(16) To meet this high-standard criterion, the use of adsorbent materials to selectively capture this pollutant can be a promising solution. $(17,18)$ The most common adsorbents, for example, zeolites and activated carbons, have been intensively considered for the capture of a range of volatile organic compounds.(19) However, acetic acid raises additional challenges compared to that of other less hydrophilic compounds due to its potential competitive adsorption with water under normal humidity storage conditions of cultural artifacts (relative humidity $(\mathrm{RH})$ above $40 \%$; above $0.4 p / p^{0}$ of water pressure). Humidity is usually controlled to prevent degradation caused by high moisture(13) and excessive hydration-dehydration cycles of the materials.(20) In this context, zeolites such as $\mathrm{NaY}$ or $\mathrm{NaX}$, used as standard adsorbents for acetic acid capture, exhibit very polar surfaces that strongly interact with this pollutant and they are then readily saturated with water at very low humidity levels.(21) In contrast, activated carbons, usually more hydrophobic than zeolites, are not saturated with water under normal relative humidity conditions (between 40 and 60\%).(21) However, these porous solids do not strongly bind acetic acid. Other alternatives including the use of metalcontaining polymer films, which capture acetic acid via an oxidation of the metal, can also be designed for storage of cultural artifacts and art. These films form a barrier for the entry of oxidizing agents but, unfortunately, are not sufficiently transparent for displaying items at museums. Thus, the development of new materials for this high-end application is required. Here, we report how some particular porous hybrid materials can circumvent the drawbacks outlined above, allowing a selective capture of very low concentrations of acetic acid over water in museum showcases and indoor air with unprecedented performances.

The family of metal-organic frameworks (MOFs) is a versatile class of porous hybrid crystalline architectures, developed during the last few decades, made 
from the quasi-infinite association of inorganic moieties and organic linkers, forming micro- or mesoporous materials whose pore size, shape, surface area, and hydrophilic/hydrophobic balance can easily be tuned toward a wide range of potential applications.(22-24) In the field of adsorption, MOFs show the advantage of incorporating a large variety of potential active sites (Lewis, Bronsted, or redox) in their frameworks that can interact specifically with polar or quadrupolar molecules (e.g., $\mathrm{CO}, \mathrm{NO}$, or $\mathrm{CO}_{2}$ ), thus favoring their selective adsorption toward more inert species (e.g., alkanes). The selective capture of these molecules, over water, is however much more challenging because there is usually a competitive adsorption over the same adsorption sites most often in favor of water owing to the more energetic $\mathrm{H}_{2} \mathrm{O}$-porous framework interactions. Propitiously, several strategies can be envisaged to design porous hybrid materials able to selectively adsorb guest molecules over water. This can be the following. (i) A MOF containing distinct adsorption sites for both molecules. This was recently demonstrated with KAUST-8, which allows the concomitant adsorption of $\mathrm{H}_{2} \mathrm{O}$ and $\mathrm{CO}_{2}$ in coordinatively unsaturated metal sites and fluorine arrays, respectively.(25) (ii) A hydrophobic MOF with either the absence of polar groups in the inorganic nodes (e.g., $-\mathrm{OH}$ ) and/or the presence of organic linkers bearing hydrophobic groups (e.g., $\mathrm{CH}_{3}$ or $\mathrm{CF}_{3}$ ); typically, the hydrophobic Zr-based MOFs, denoted MIL-140s, were shown to adsorb selectively phenol derivatives over water.(26) (iii) An amphiphilic MOF containing distinct hydrophobic and hydrophilic regions in the pores can offer an optimal scenario with a synergistic effect of water as a contaminant to enhance the $\mathrm{CO}_{2} / \mathrm{N}_{2}$ or $\mathrm{CO}_{2} / \mathrm{CH}_{4}$ selectivity; however, most of the time it was associated with a decrease in the overall $\mathrm{CO}_{2}$ capture capacity.(27) (iv) In some rare cases, it has even been shown that highly energetic adsorption sites incorporated in some MOFs, such as the coordinatively unsaturated metal sites, allow a preferential binding of one guest molecule over water. This is the case of the iron trimesate-based MIL-100(Fe) that selectively adsorbs phosphated drug molecules from aqueous solutions.(28) Many other examples about the removal of organic pollutants from water can be found elsewhere. $\underline{(29,30)}$

We capitalized on the unique versatility of this class of porous materials in terms of chemical composition and pore size/topology to identify MOFs with optimal performances for the selective removal of acetic acid, under the conditions encountered at museums, that is, in the presence of air moisture. This challenging objective calls for a systematic exploration of the adsorption/separation properties for a series of water-stable MOFs with different pore sizes, shapes, hydrophobicities, and functionalities (see Figure 1), including basic amine groups or fluorine moieties, to further reveal the key parameters that drive the selective acetic acid removal in the presence of moisture. To that purpose, four different MOF architectures known for their chemical robustness were initially selected (see Figure 1 and Table 1). First is the mesoporous hydrophobic three-dimensional cagelike chromium terephthalate, MIL-101 (cage dimensions of 2.9 and $3.4 \mathrm{~nm}$ ), owing to the presence of coordinatively unsaturated metal sites (Lewis acid sites) that can 
potentially act as strong adsorption sites for the acetic acid and to its very large pore volume to ensure high acetic acid uptake. Its functionalized analogue bearing basic ethylenediamine (=en) grafted postsynthetically on the metal acid sites (MIL-101-en; Figure 1)(31) was also selected not only to understand whether replacing the metal acid sites by basic amine groups would improve the performance but also taking into account that such amine groups are known to be much less water sensitive than free metal sites when capturing $\mathrm{CO}_{2}$, an acidic gas, in the presence of humidity.(32,33)

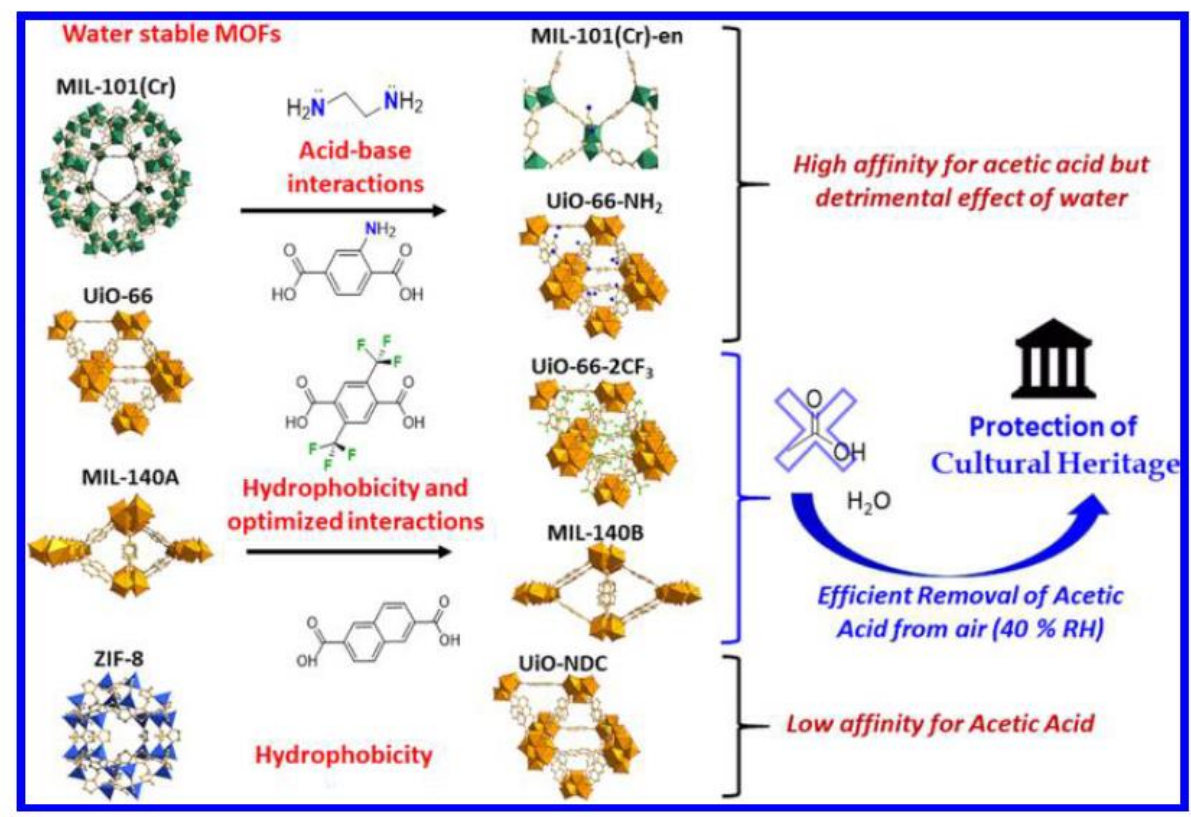

Figure 1. Four MOF architectures-MIL-101 type, UiO-66 type, MIL-140 type, and ZIF type-were explored with several modifications to enhance the selective capture of acetic acid in the presence of water. Grafting of amines in unsaturated metal sites of MIL-101 using naphthalene dicarboxylate (NDC) as linker and functionalization of linker with amines and bulky hydrophobic $-\mathrm{CF}_{3}$ groups were the main routes explored (see main text). Color codes: $\mathrm{Zr}$ polyhedra in yellow, Cr octahedra in green, and $\mathrm{Zn}$ tetrahedra in blue; oxygen in red, nitrogen in blue, fluorine in green, and carbon in gray (hydrogens were omitted for simplicity).

Table 1. Textural Properties of the Studied MOF Materials

\begin{tabular}{llll} 
material & $\boldsymbol{A}_{\text {BET }}\left(\mathbf{m}^{2} \mathbf{g}^{-1}\right) \underline{\mathbf{a}}$ & $\boldsymbol{V}_{\mu}\left(\mathbf{c m}^{3} \mathbf{g}^{-1}\right) \underline{\mathbf{b}}$ & $\boldsymbol{A}_{\text {ext }}\left(\mathbf{m}^{2} \mathbf{g}^{-1}\right) \underline{\mathbf{b}}$ \\
\hline MIL-101-Cr & 3606 & 1.580 & 102 \\
\hline MIL-101-Cr-en & 1153 & 0.508 & 45 \\
\hline UiO-66 & 892 & 0.379 & 17
\end{tabular}




\begin{tabular}{llll}
\hline material & $\boldsymbol{A}_{\text {BET }}\left(\mathbf{m}^{2} \mathbf{g}^{-1}\right) \underline{\mathbf{a}}$ & $\boldsymbol{V}_{\mu}\left(\mathbf{c m}^{3} \mathbf{g}^{-1}\right) \underline{\mathbf{b}}$ & $\boldsymbol{A}_{\text {ext }}\left(\mathbf{m}^{2} \mathbf{g}^{-1}\right) \underline{\mathbf{b}}$ \\
\hline UiO-66-NH & 966 & 0.424 & 15 \\
\hline UiO-66-2CF & 467 & 0.184 & 39 \\
\hline UiO-NDC & 1362 & 0.586 & 30 \\
\hline MIL-140A & 317 & 0.132 & 17 \\
\hline MIL-140B & 363 & 0.119 & 91 \\
\hline ZIF-8 & 1348 & 0.529 & 52
\end{tabular}

Specific surface area $\left(A_{\text {вЕT }}\right)$ calculated by application of the BET equation in the linear form to data between 0.04 and $0.15 p / p^{0}$.

-Microporous volume $\left(V_{\mu}\right)$ and external surface area $\left(A_{\text {ext }}\right)$ calculated by the $t$ plot method using the Harkins-Jura reference equation between 0.4 and 0.8 nm. (34)

The second series comprises several derivatives of the microporous cagelike three-dimensional $\mathrm{Zr}$ dicarboxylate, UiO-66 structure type (tetrahedral and octahedral cage dimensions of 0.8 and $1.1 \mathrm{~nm}$, respectively) bearing (i) pending $-\mathrm{NH}_{2}$ or $-\mathrm{CF}_{3}$ groups substituted in the terephthalate linker, that is, UiO-66- $\mathrm{NH}_{2}$ and UiO-66-2CF , respectively, or (ii) extended organic linker, that is, the analogue UiO-NDC (cage dimensions of 1.0 and $1.3 \mathrm{~nm}$ ) with a longer spacer (2,6-naphthalene dicarboxylate (2,6-NDC) vs terephthalate (BDC) for UiO-66) (Figure 1). The third family of MOF is the channel-like $\mathrm{Zr}$ oxide dicarboxylates, MIL-140A and MIL-140B (pore dimensions of 0.32 and $0.4 \mathrm{~nm}$, respectively), built from 1,4-BDC and 2,6-NDC linkers, respectively (Figure 1), because these hydrophobic small-pore MOFs have already shown promises for the capture of organics in solution.(35) Finally, the hydrophobic microporous three-dimensional Zn imidazolate, ZIF-8 (pores of 1.1 $\mathrm{nm}$ ),(36) was also considered owing to its very high hydrophobicity (Figure 1).

Here, the overall objective was, first, to reinforce the degree of hydrophobicity of the MOF with the inclusion of lipophilic groups $\left(-\mathrm{CF}_{3}\right)$ and then, second, to enhance the acetic acid-MOF interactions either (i) incorporating $-\mathrm{NH}_{2}$ groups in the MOF framework to preferentially interact with the $-\mathrm{CO}_{2} \mathrm{H}$ function of the acetic acid via hydrogen bonds or (ii) replacing the phenyl by a naphthyl spacer to increase the van der Waals (vdW) interactions between the organic linker and the alkyl chain $\left(-\mathrm{CH}_{3}\right)$ of the acetic acid and (iii) modulating the degree of confinement via the steric hindrance of organic linkers of different lengths and functionalities (Figure 1). The synthesis procedures and characterization results of all MOFs tested are presented in the Supporting Information (SI). 


\section{Experimental Section}

\subsection{Synthesis and Characterization of the Metal-Organic Frameworks}

Detailed description of the synthesis procedures can be found in SI. All synthesized MOFs were characterized, and the results were analyzed to confirm the successful synthesis and purity of the materials. Nitrogen (air liquid, 99.999\%) adsorption-desorption isotherms were measured at $-196{ }^{\circ} \mathrm{C}$ using a liquid nitrogen cryogenic bath, in a volumetric automatic apparatus (Micromeritics, ASAP 2010). The X-ray powder diffraction patterns were obtained with a high-resolution D5000 Siemens X'Pert MDP diffractometer ( $\lambda_{\text {cu, }}$ $\mathrm{Ka}_{1}, \mathrm{Ka}_{2}$ ). Thermogravimetric analysis was performed with a thermogravimetric analyzer (model PerkinElmer STA 6000) in air at a constant heating rate of 2 ${ }^{\circ} \mathrm{C}$ min $^{-1}$. Transmission IR spectra have been recorded with a Nicolet Nexus spectrometer in the range from 4000 to $500 \mathrm{~cm}^{-1}$ with a resolution of $4 \mathrm{~cm}^{-1}$. Further experimental details and analyses of results are presented in the SI.

\subsection{Pure Water and Acetic Acid Adsorption}

The adsorption isotherms of water were determined at $30.0 \pm 0.1^{\circ} \mathrm{C}$ in an automated apparatus, model Omnisorp 100cx (Coulter), using a fixed vapor dosing method. Adsorption isotherms of acetic acid were measured by the volumetric method at low relative pressure, in a lab-made glass adsorption line. Adsorption temperature was maintained with a water bath (Grant GD120) at $25^{\circ} \mathrm{C}$. The pressure was measured with a capacitance transducer from Pfeiffer Vacuum (CMR 262). Additional experimental details are given in the SI.

\subsection{Acetic Acid Adsorption in Controlled Relative Humidity}

About $50 \mathrm{mg}$ (Mettler AE240) of the sample previously dried overnight in an oven at $100^{\circ} \mathrm{C}$ was placed inside a closed chamber $\left(2.9 \mathrm{dm}^{3}\right)$ at $40 \%$ relative humidity for $1.5 \mathrm{~h}$ to equilibrate the moisture content. After this time, $1 \mu \mathrm{L}$ of acetic acid (Riedel-de Haën, 99.8\%) was injected with a syringe (Hamilton $7001 \mathrm{KH}$ ) inside the chamber through a rubber septum injection port, in the surface of a clean paper filer to improve the spreading and evaporation of the small droplet. The total acetic acid concentration, temperature, and relative humidity inside the chamber were measured (Graywolf TG-502 TVOC ppb) and were recorded at fixed time intervals $(15 \mathrm{~s})$ for at least $1 \mathrm{~h}$ using computer software (Wolfsense LAP). A blank experiment with no injection of acetic acid 
was performed, and a control experiment was performed with injection of acetic acid without any MOF to demonstrate the tightness of the chamber during the time frame of the experiments and ascertain the TVOC signal response obtained by $1 \mu \mathrm{L}$ injection. Additional experimental details are given in the SI.

\subsection{Computational Methods}

Preliminary geometry optimizations of the water- and acetic acid-loaded crystal structures of UiO-66, UiO-66-2 $\mathrm{CF}_{3}$, and MIL-140B were performed at the density functional theory level. These structure models were further employed to run Monte Carlo simulations in the NVT ensemble to obtain insights into the most preferential distribution of the two guest molecules in the porosity as a single component and mixtures and to identify the nature and strength of interactions between these guests and the MOF framework. All computational details are given in the SI.

\section{Results}

\subsection{Adsorption of Acetic Acid and Water}

The adsorption of acetic acid and water as single components was first investigated (Figure 2). The volume of adsorbed acetic acid (Figure S31b) is well below the volume obtained from nitrogen porosimetry (Figure S31), showing that the pores are far from being saturated with acetic acid at low pressures. The isotherms have been collected for acetic acid up to $0.15 p / p^{0}$, with most of the points below $0.02 p / p^{0}(0.04 \mathrm{kPa}$; detail of the low-pressure domain is provided in Figure S31a), which corresponds to about 400 ppm (1 g $\left.\mathrm{m}^{-3}\right)$. Note that this concentration is several hundred times higher than that found in museum showcases, $(6,7,9,10,14,15)$ meaning that the efficiency will not be dependent on the saturation capacity of MOFs. In this context, the affinity of the material for acetic acid that can be assessed by the slope of the adsorption isotherm at low coverage and more precisely by the estimation of Henry's constant $\left(K_{H}\right)$ is more relevant for the analysis of the material's performance. Moreover, the results show that the amounts of acetic acid adsorbed at the low concentrations (Figure 2) are not correlated with the textural features of the materials (Table 1 ). Indeed, as discussed in the following section, the acetic acid adsorption rather strongly depends on the nature of the chemical groups present at the MOF pore wall. 


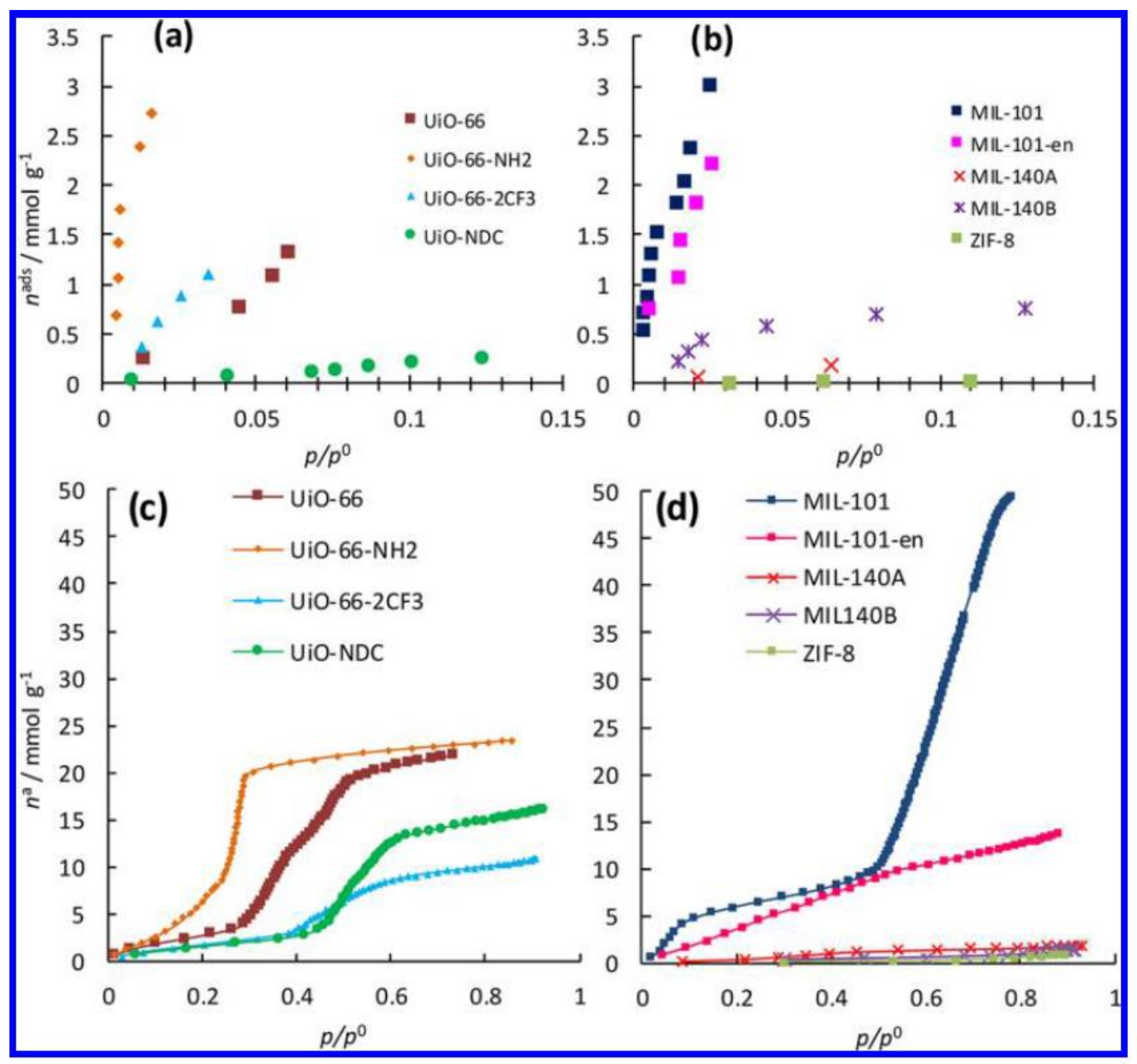

Figure 2. Acetic acid adsorption isotherms at $25^{\circ} \mathrm{C}$ (a) and (b) and water adsorption isotherms at $30^{\circ} \mathrm{C}$ (c) and (d) of the title MOFs.

The acetic acid adsorption isotherms depicted in Figure 2a show that in the low domain of pressure, $\mathrm{UiO}-66-\mathrm{NH}_{2}$ exhibits the highest uptake, even slightly higher than that for the mesoporous MIL-101 (Figure 2b). Compared to the parent UiO-66, one can see that the introduction of the amine group leads to a steeper adsorption isotherm at low pressure, concomitant with a 9-fold increase of Henry's constant (Table 2). This is due, as expected, to the acidbase interactions and hydrogen bonding between the $-\mathrm{NH}_{2}$ function of the MOF and the acetic acid $-\mathrm{CO}_{2} \mathrm{H}$ group. Interestingly, this Henry's constant is similar to that obtained for MIL-101, although a higher affinity would have been expected owing to the potential strong binding of the acetic acid to the coordinatively unsaturated sites. This observation emphasizes that in addition to the interactions between $-\mathrm{NH}_{2}$ and acetic acid, the confinement of this guest into the relatively small cages of $\mathrm{UiO}-66-\mathrm{NH}_{2}$ plays a key role in the high affinity. Similarly, MIL-101 and MIL-101-en both adsorb a comparable amount of acetic acid (Figure 2b). It should be reminded that $-\mathrm{NH}_{2}$ groups of ethylenediamine substitute the uncoordinated metal sites in MIL-101 for acetic acid binding and these groups are in principle less strong adsorption sites. However, this is compensated by an increase of the confinement effect as a 
result of the decrease in pore volume of this solid (Table 1). When it comes to analyzing the effect of the $-\mathrm{CF}_{3}$ groups on the UiO-66 structure through a comparison with the parent UiO-66 (Figure 2a and Table 2), although the presence of $-\mathrm{CF}_{3}$ groups leads to a significant decrease of the accessible surface area (Table 1), it drastically improves the adsorption of acetic acid at low pressures. This might be ascribed both to the strong interaction of acetic acid with the $-\mathrm{CF}_{3}$ groups and to the higher degree of confinement of acetic acid in the narrower pores of $\mathrm{UiO}-66-2 \mathrm{CF}_{3}$ (this interaction and the confinement effect are discussed in detail in Section 3.3). Finally, in the case of the hydrophobic MIL-140A, MIL-140B, and ZIF-8 materials, the adsorbed amounts are significantly smaller than for the other tested MOFs due to the absence of any polar groups that can interact specifically with acetic acid. However, when comparing MIL-140A and MIL-140B, a significant increase of affinity at low pressure (Henry's constant; see Table 2) is observed for the latter due to stronger interactions between the naphthyl spacer and acetic acid and to a better accessibility of acetic acid to the pores.

Table 2. Henry's Constants of Acetic Acid Adsorption at $25{ }^{\circ} \mathrm{C}\left(K_{\mathrm{H}}\right)$ and Water Adsorption at $30^{\circ} \mathrm{C}\left(K_{\mathrm{w}}\right)$

$$
\text { mean } \pm \mathrm{SD}
$$

\begin{tabular}{llll}
\hline material & $\boldsymbol{K}_{\mathbf{H}} \mathbf{a}\left(\mathbf{m m o l} \mathbf{g}^{-1}\right)$ & $\boldsymbol{K}_{\mathbf{H}}\left(\mathbf{g}_{\text {vapor }} \mathbf{g}^{-1}{ }_{\text {sample }}\right)$ & $\boldsymbol{K}_{\mathbf{w}} \underline{\mathbf{b}}\left(\mathbf{m m o l} \mathbf{g}^{-1}\right)$ \\
\hline MIL-101-Cr & $212 \pm 7$ & $12.7 \pm 0.4$ & $46.8 \pm 2.5$ \\
\hline MIL-101-Cr-en & $89 \pm 5$ & $5.4 \pm 0.3$ & $18.3 \pm 0.1$ \\
\hline UiO-66 & $21 \pm 1$ & $1.2 \pm 0.1$ & $20.4 \pm 2.9$ \\
\hline UiO-66-NH & $193 \pm 21$ & $11.6 \pm 1.3$ & $27.2 \pm 1.2$ \\
\hline UiO-66-2CF & $33 \pm 1$ & $2.0 \pm 0.1$ & $7.0 \pm 0.5$ \\
\hline UiO-NDC & $2.1 \pm 0.4$ & $0.12 \pm 0.03$ & $2.1 \pm 0.2$ \\
\hline MIL-140A & $2.1 \pm 0.1$ & $0.13 \pm 0.01$ & $1.00 \pm 0.02$ \\
\hline MIL-140B & $19 \pm 1$ & $1.13 \pm 0.07$ & $0.367 \pm 0.002$ \\
\hline ZIF-8 & $0.5 \pm 0.1$ & $0.03 \pm 0.01$ & \\
\hline
\end{tabular}

Calculated from the initial slope of the isotherms in Figure 2a,b.

Calculated from the initial slope of the isotherms in Figure $2 \mathrm{c}, \mathrm{d}$. 
Amounts of acetic acid adsorbed on activated carbons, $\mathrm{NaY}$ and $\mathrm{NaX}$ zeolites, which are, to our knowledge, among the best porous materials tested so far for such an application, are on average close to $1.7 \mathrm{mmol} \mathrm{g}^{-1}$ at $0.02 \mathrm{p} / \mathrm{p}^{\circ}(18)$ with a relatively linear profile in the low-pressure range. At first sight, this tendency is reminiscent of that obtained for our series of MOFs (Figure 2a,b). However, UiO-66-NH $\mathrm{NH}_{2}, \mathrm{MIL}-101$, and MIL-101-en significantly overpass these performances (Figure 2a,b). This is consistent with the higher magnitude of Henry's constants of these three solids compared to that of zeolites, activated carbons, silica gel, and porous clays, which range between 4.30 and 1.06 $\mathrm{g}_{\text {vapor }} \mathrm{g}^{-1}$ sample. (18) In contrast, UiO-NDC, MIL-140A, and ZIF-8 exhibit lower Henry's constants. As a first screening, one would be tempted to select MOFs with higher affinity for the acetic acid at low pressures than the reference adsorbents.

Water adsorption isotherms (Figure 2c, d) were further measured to make a correlation between the water affinity of these MOFs and their structural/chemical parameters. The results confirm that polar $-\mathrm{NH}_{2}$ functional groups (UiO-66- $\mathrm{NH}_{2}$ ) and/or coordinatively unsaturated metal sites (MIL-101, MIL-101-en) lead, as expected, to a higher affinity for water at low pressures, whereas the most hydrophobic MOFs (MIL-140, UiO-NDC, ZIF-8) adsorb only negligible amounts of water. $\mathrm{UiO}-66$ and $\mathrm{UiO}-66-2 \mathrm{CF}_{3}$ adsorb water in two steps, which is associated with their two types of tetrahedral and octahedral cages of different dimensions. Noteworthy, for the latter, the presence of $-\mathrm{CF}_{3}$ groups, mostly pointing toward the octahedral cages, induces a significant shift of the second adsorption step to higher pressures, that is, far above the $40 \%$ relative humidity found in museums. A detailed discussion on the effects of pore size and surface groups in water adsorption is given in the SI. It is worth mentioning that the surface area of the materials was considered in this discussion for a proper comparison of the performances of these materials.

In the context of acetic acid removal, because the most difficult challenge for a sorbent is to adsorb acetic acid without suffering from the competition between water and acetic acid adsorption that typically always occurs under common conditions at museums (i.e., above $0.4 p / p^{0}$ of water pressure), our first results strongly suggest that acetic acid adsorption in the presence of air humidity can be enhanced through a fine tuning of the ligand functionalization and/or pore size engineering.

\subsection{Capture of Acetic Acid in the Presence of Water}

To assess the behavior of these MOFs under real conditions, tests to remove trace amounts of acetic acid from air in the presence of water, that is, $40 \%$ relative humidity $(\mathrm{RH})$ typically present in museums, were performed. The removal of acetic acid from the environment must also be relatively rapid because it can react irreversibly with artifacts, forming acetate salts. $(10,13)$ Thus, the adsorption kinetics were equally considered. A few 
reference materials typically considered for this application, zeolite $\mathrm{NaY}$ and activated carbon RB4, were also selected as benchmarks for further comparison.

The injection of minor amounts of acetic acid in a closed chamber (corresponding to $362 \mu \mathrm{g} \mathrm{dm}^{-3}$ ) with controlled $\mathrm{RH}$ allowed the determination of comparative profiles of acetic acid removal by the MOFs (for guidance, $100 \mu \mathrm{g}$ $\mathrm{dm}^{-3}$ is equivalent to $40 \mathrm{ppm}$ in volume). There is an initial rise of the concentration due to the combined effect of the diffusion inside the chamber and the simultaneous adsorption (Figure 3), followed by a decrease due to the removal of acetic acid by the adsorbents. In their absence, this decrease does not occur, and only a faster rise is observed (Figure S34a). UiO-66 and MIL101 , both of which exhibit an intermediate hydrophobic character, led to interesting results, decreasing the acetic acid concentrations down to 26.9 and $23.3 \mu \mathrm{g} \mathrm{dm}^{-3}$, respectively, after $1 \mathrm{~h}$. As expected, the introduction of amine groups in these materials did not improve the performance, that is, MIL-101en: $41.6 \mu \mathrm{g} \mathrm{dm}^{-3}$ (Figure 3b) and UiO-66- $\mathrm{NH}_{2}: 34.6 \mu \mathrm{g} \mathrm{dm}{ }^{-3}$ (Figure 3a) after 1 $h$. This confirms the above-mentioned assumption that enhancing the affinity toward acetic acid is not efficient if not associated with a significant increase of hydrophobicity. On the contrary, the very hydrophobic ZIF-8 shows a promising performance with a concentration of $20.2 \mu \mathrm{g} \mathrm{dm}^{-3}$ reached after $1 \mathrm{~h}$. This is very close to that obtained with UiO-NDC $\left(20.5 \mathrm{\mu g} \mathrm{dm}^{-3}\right.$ after 1 h; Figure 3a), which slightly overcomes UiO-66, probably due to the antagonist effects of a slightly higher hydrophobicity for UiO-NDC and a lowering of the confinement effect due to the significant increase in the pore size (Figure 1). In contrast, a strong enhancement is observed from MIL-140A to MIL-140B, with the final acetic acid concentrations ranging from 34.5 to $12.2 \mu \mathrm{g} \mathrm{dm}-$ ${ }_{3}^{3}$ (Figure 3a). Because both materials are hydrophobic, the higher performance of MIL-140B may be ascribed both to an increase in pore size that enables a better accessibility to the pores of MIL-140B but not for MIL-140A and to the slightly stronger interaction between the methyl group of acetic acid and the naphthyl spacer. For the sake of understanding the pore size effect, if the larger pore analogue MIL-140C $(0.57 \mathrm{~nm})(35)$ is considered, the lower confinement effect leads finally to a lower efficiency of this solid compared to that of MIL-140B (see Figure S34b). Finally, the best material was found to be UiO-66-2 $\mathrm{CF}_{3}$ (Figure 3a) for which the fastest decrease was observed, attaining $7.2 \mu \mathrm{g} \mathrm{dm}^{-3}$ after $1 \mathrm{~h}$. Compared to UiO-66, the higher performance of UiO-66-2 $\mathrm{CF}_{3}$ might arise from a stronger interaction between the MOF framework and the acetic acid that acts concomitantly with its higher hydrophobicity. 


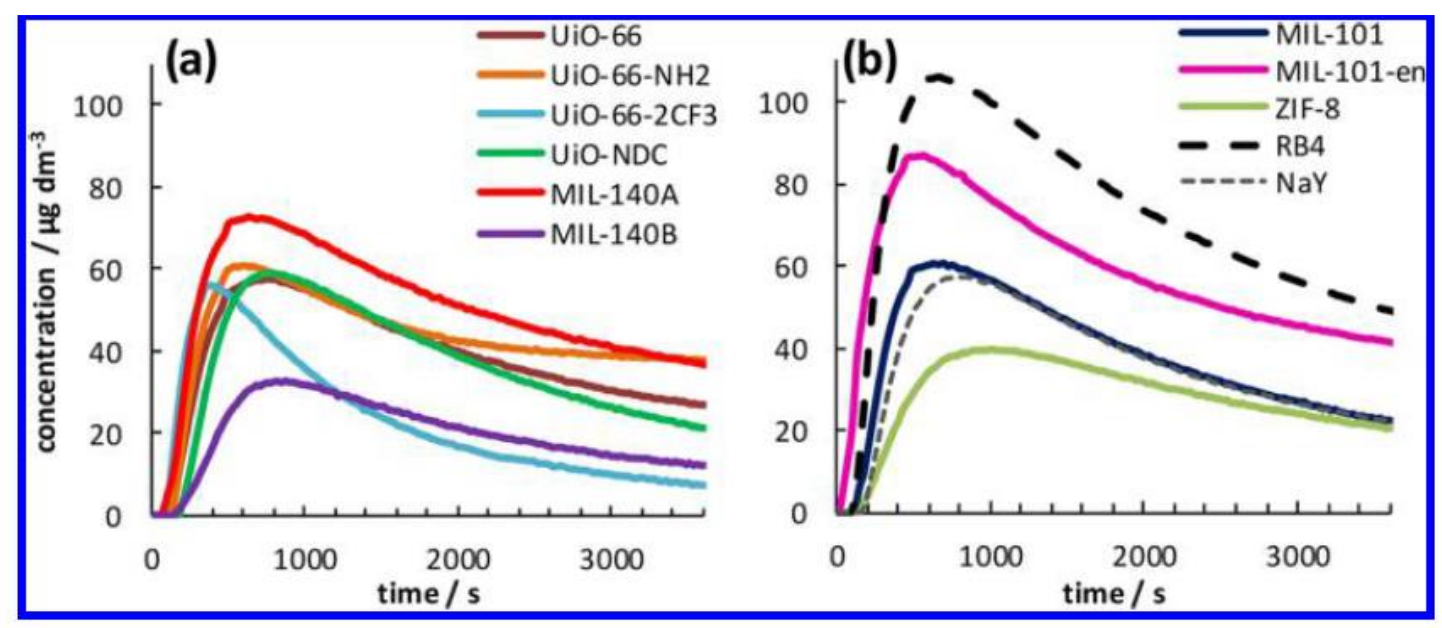

Figure 3. Acetic acid concentration profiles inside a closed chamber after the injection of $1 \mu \mathrm{L}$ of acetic acid at $23^{\circ} \mathrm{C}, 40 \% \mathrm{RH}$, in the presence of $50 \mathrm{mg}$ of: (a) UiO-66, UiO-66-NH 2 , UiO-66-2CF, UiO-NDC, MIL-140A, and MIL-140B; and (b) MIL-101-Cr, MIL-101-Cr-NH 2 , ZIF-8, activated carbon RB4, and zeolite $\mathrm{NaY}$.

A comparison of the results obtained on the chamber with that of the adsorption isotherms, for the best MOFs, indicates that the acetic acid adsorption on ZIF-8 is already approaching equilibrium, whereas for UiO-66$2 \mathrm{CF}_{3}$ and MIL-140B, this is not the case (see additional discussion in SI). Indeed, the concentration in the chamber is still decreasing considerably at $1 \mathrm{~h}$ (Figure 3), with a drop down to 4.2 and $9.5 \mu \mathrm{g} \mathrm{dm}^{-3}$ after $1.5 \mathrm{~h}$ for UiO-66$2 \mathrm{CF}_{3}$ and MIL-140B, respectively (not shown on Figure 3). The performance was finally compared to that of zeolite ( $\mathrm{NaY}$ ) and an activated carbon (RB4).(18) Noteworthy, these materials are less efficient than most MOFs (Figure 3); all MOFs outperform the activated carbon RB4, whereas UiO-66, UiO-NDC, ZIF-8, and MIL-101 present a similar behavior to that of NaY. Remarkably, the acid adsorption properties of MIL-140B and UiO-66-2CF 3 are significantly better than those of zeolite and activated carbon, demonstrating that these materials, particularly $\mathrm{UiO}-66-2 \mathrm{CF}_{3}$, are the most suitable MOF candidates for an efficient acetic acid removal in the presence of moisture. However, because the ligand used for the synthesis of UiO-66-2 $\mathrm{CF}_{3}$ is obtained only after several long synthesis steps, the MIL-140B may be regarded as a suitable alternative at eventually lower costs because this material is based on the standard NDC ligand. A summary of the relevant properties of the whole MOFs considered for their application for acetic acid removal in the presence of moisture is presented in Table S6. 


\subsection{Computational Study of the Adsorption and Coadsorption in $\mathrm{UiO}-66-2 \mathrm{CF}_{3}$ and MIL-140B}

A computational approach coupling density functional theory and force-fieldbased Monte Carlo simulations (see SI) was deployed to shed light on the microscopic mechanism at the origin of the selective adsorption of acetic acid under a relative humidity of $40 \%$ in the best MOFs, that is, UiO-66-2- $\mathrm{CF}_{3}$ and MIL-140B. For UiO-66-2 $\mathrm{CF}_{3}$, in mixture adsorption, $\mathrm{CH}_{3} \mathrm{CO}_{2} \mathrm{H}$ preferentially adsorbs in the more confined tetrahedral cages. Although the two $-\mathrm{CF}_{3}$ groups in the terephthalate linker are pointing toward the large octahedral cages, still their $\mathrm{F}$ atoms in the bulkier $-\mathrm{CF}_{3}$ groups are very much in the vicinity of the guest molecules present in the confined tetrahedral cages (see Figure 4a). $\mathrm{CH}_{3} \mathrm{CO}_{2} \mathrm{H}$ interacts relatively strongly with the pore wall through (i) their $\mathrm{O}$ atoms with the $\mu_{3}(\mathrm{OH})$ groups $\left(\mathrm{O} \_\mathrm{CO}_{\text {acetic acio }}-\mathrm{H}_{-} \mu_{3}(\mathrm{OH})=1.8 \AA\right.$; Figure S40) and (ii) their $\mathrm{H}$ atoms with the $\mathrm{F}$ atoms of the $-\mathrm{CF}_{3}$ groups $\left(\mathrm{H}_{-} \mathrm{OH}_{\text {acetic acio }}-\mathrm{F}=2.01\right.$ $\AA$; Figure S40; and $\mathrm{H}_{-} \mathrm{CH}_{\text {3acetic acid }}-\mathrm{F}=2.3 \AA$; Figure S40). This scenario is similar to that observed for the adsorption of acetic acid as a single component (SI). In contrast, $\mathrm{H}_{2} \mathrm{O}$ molecules occupy both octahedral and tetrahedral cages, forming isolated clusters that are strongly hydrogen-bonded $\left(\mathrm{O}_{\mathrm{H}_{2}} \mathrm{O}-\mathrm{H}_{\mathrm{H}_{2} \mathrm{O}=1.80}\right.$ $\AA$; Figure S40) with only weak interactions with the pore walls. This behavior is consistent with the hydrophobic character of the solid, as confirmed by a low simulated adsorption enthalpy at low coverage for $\mathrm{H}_{2} \mathrm{O}\left(<-40 \mathrm{~kJ} \mathrm{~mol}^{-1}\right.$; Table S8). The two-dimensional density probabilities of both $\mathrm{CH}_{3}-\mathrm{CO}_{2} \mathrm{H}$ and $\mathrm{H}_{2} \mathrm{O}$ in UiO-66-2- $\mathrm{CF}_{3}$ and the most representative host-guest interactions provided in Figure 4 illustrate the microscopic coadsorption mechanism in play. This figure emphasizes that there is no competitive adsorption in the octahedral cages (only water), whereas in the tetrahedral cages, both species coexist. However, a comparison with the results in the nonfunctionalized UiO-66 clearly evidences that $-\mathrm{CF}_{3}$ groups not only favor a higher hydrophobic character but also, remarkably, create a higher affinity to the acetic acid. This is revealed by a significant increase of the simulated adsorption enthalpy for acetic acid (-68 $\mathrm{kJ} \mathrm{mol}^{-1}$ for UiO-66-2CF 3 vs only $-42 \mathrm{~kJ} \mathrm{~mol}^{-1}$ for UiO-66; Table S8), confirming that both the higher hydrophobicity and the stronger interaction with acetic acid contribute to a drastic enhancement of the selective adsorption of $\mathrm{CH}_{3}-\mathrm{CO}_{2} \mathrm{H}$ over $\mathrm{H}_{2} \mathrm{O}$ driven by thermodynamics consideration. 


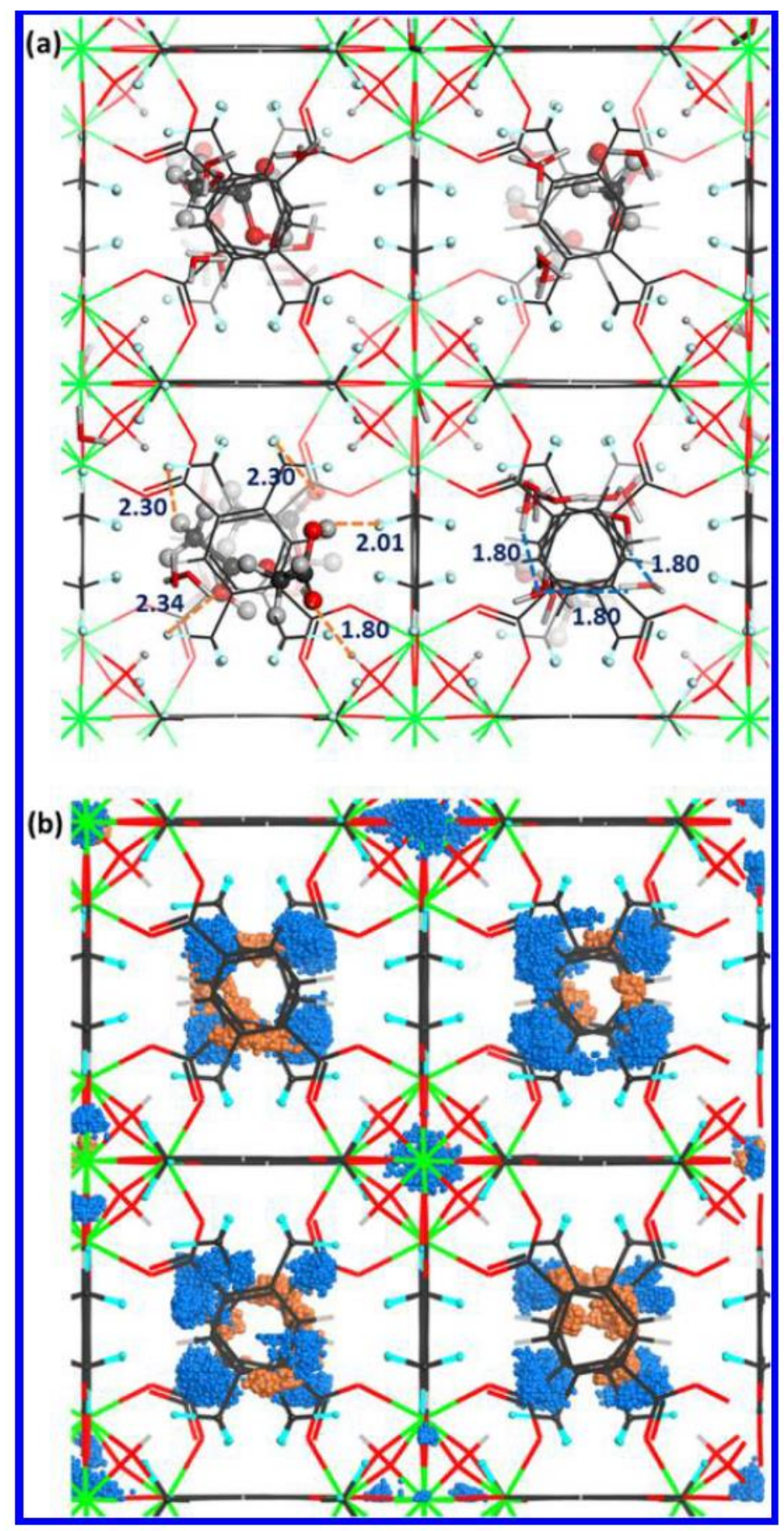

Figure 4. (a) Monte Carlo simulated arrangements of $\mathrm{CH}_{3}-\mathrm{CO}_{2} \mathrm{H}$ and $\mathrm{H}_{2} \mathrm{O}$ molecules from a binary mixture in $\mathrm{UiO}-66-2 \mathrm{CF}_{3}$ at $298 \mathrm{~K}\left(\mathrm{CH}_{3}-\mathrm{CO}_{2} \mathrm{H} / \mathrm{H}_{2} \mathrm{O}\right.$ with composition of $1.2 / 3 \mathrm{mmol} \mathrm{g}^{-1}$ ). (b) Maps of the occupied positions of the binary mixture for $\mathrm{CH}_{3}-\mathrm{CO}_{2} \mathrm{H}$ and $\mathrm{H}_{2} \mathrm{O}$ in 1000 equilibrated frames in UiO-66$2 \mathrm{CF}_{3}$ with $1.2 / 3 \mathrm{mmol} \mathrm{g}{ }^{-1}$ for $\mathrm{CH}_{3}-\mathrm{CO}_{2} \mathrm{H} / \mathrm{H}_{2} \mathrm{O}$ at $298 \mathrm{~K}$. Color code for the framework atoms: $\mathrm{C}$ (dark gray), $\mathrm{O}$ (red), $\mathrm{F}$ (cyan), $\mathrm{H}$ (light gray), $\mathrm{Zr}$ (green), the guest molecules: $\mathrm{CH}_{3}-\mathrm{CO}_{2} \mathrm{H}$ (orange) and $\mathrm{H}_{2} \mathrm{O}$ (blue), and the distances are reported in angstrom. 
Regarding MIL-140B, the simulated coadsorption behavior evidences that both water and acetic acid are distributed in the channels. Water molecules are found to form a strong hydrogen bond network along the tunnel with the

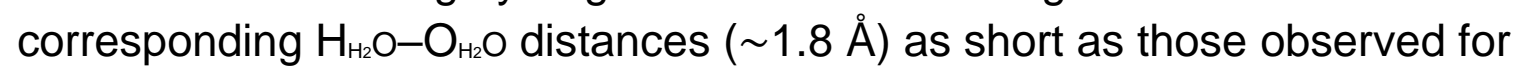
UiO-66-2 $\mathrm{CF}_{3}$ (see Figures 5 and $\mathrm{S} 41$ ). No strong anchoring sites for the acetic acid are present at the MIL-140B surface, and the molecules tend to adopt a geometry that favors interactions with the organic linker $\left(\mathrm{O} \_\mathrm{CO}_{\text {aceic acid }}\right.$ to H_organic distances above $2.5 \AA$; Figure S41). However, a high degree of confinement on the small pore channels $(4.2 \AA)$ leads to a simulated adsorption enthalpy for $\mathrm{CH}_{3}-\mathrm{CO}_{2} \mathrm{H}\left(-67 \mathrm{~kJ} \mathrm{~mol}^{-1}\right)$ comparable to that calculated in UiO-66-2 $\mathrm{CF}_{3}\left(-68 \mathrm{~kJ} \mathrm{~mol}^{-1}\right)$ (Table S8). This observation supports the fact that the selectivity in the $\mathrm{CH}_{3}-\mathrm{CO}_{2} \mathrm{H} / \mathrm{H}_{2} \mathrm{O}$ mixture adsorption in MIL-140B is mainly driven by the optimal confinement effect.

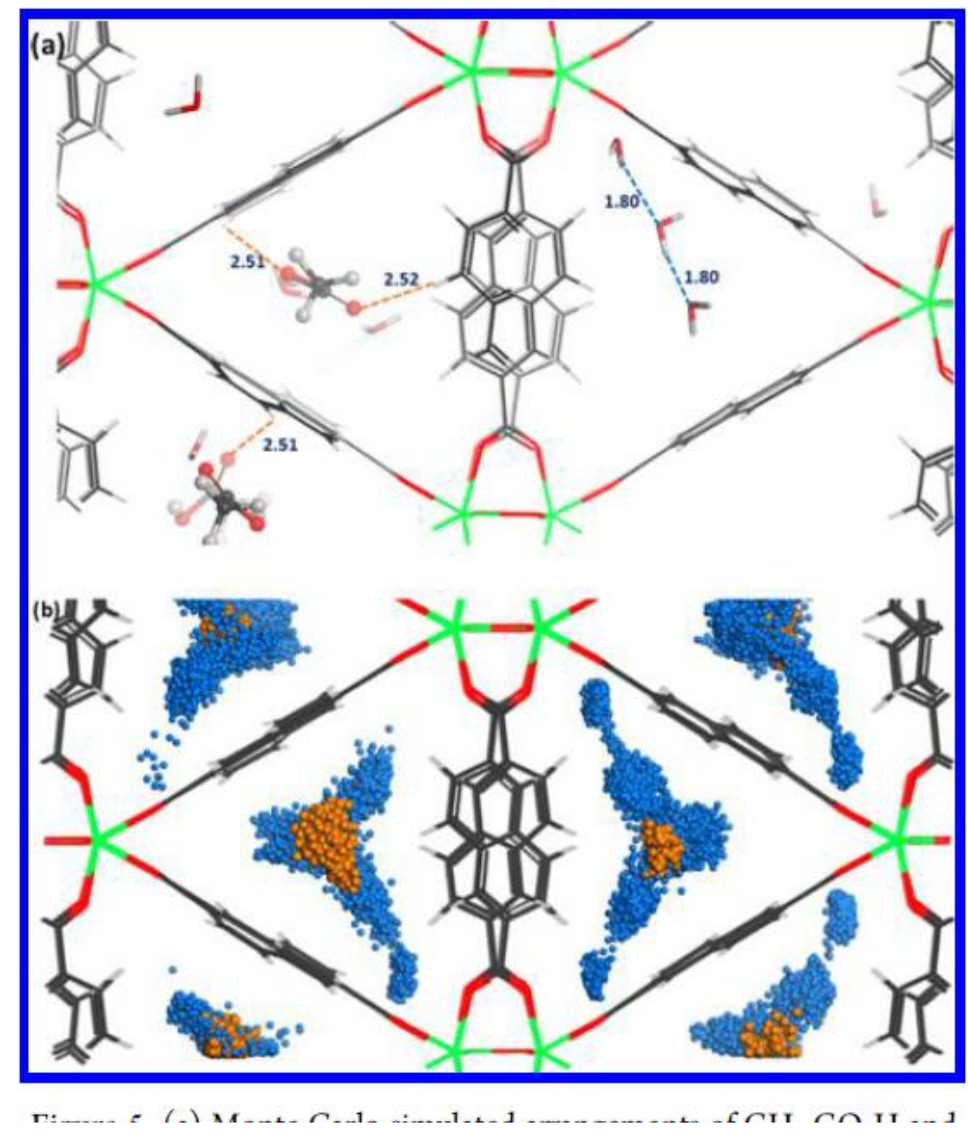

Figure 5. (a) Monte Carlo simulated arrangements of $\mathrm{CH}_{3}-\mathrm{CO}_{2} \mathrm{H}$ and $\mathrm{H}_{2} \mathrm{O}$ molecules from a binary mixture in $\mathrm{MIL}-140 \mathrm{~B}$ at $298 \mathrm{~K}\left(\mathrm{CH}_{3}-\mathrm{CO}_{2} \mathrm{H} / \mathrm{H}_{2} \mathrm{O}\right.$ with composition of $0.9 / 3 \mathrm{mmol} \mathrm{g}^{-1}$ ). (b) Maps of the occupied positions of the binary mixture for $\mathrm{CH}_{3}-\mathrm{CO}_{2} \mathrm{H}$ and $\mathrm{H}_{2} \mathrm{O}$ in 1000 equilibrated frames in MIL-140B with $0.9 / 3 \mathrm{mmol} \mathrm{g}^{-1}$ at $298 \mathrm{~K}$. Color code for the framework atoms: C (dark gray), $\mathrm{O}$ (red), $\mathrm{F}$ (cyan), $\mathrm{H}$ (light gray), $\mathrm{Zr}$ (green), the guest molecules: $\mathrm{CH}_{3^{-}}$ $\mathrm{CO}_{2} \mathrm{H}$ (orange) and $\mathrm{H}_{2} \mathrm{O}$ (blue), and the distances are reported in angstrom. 


\subsection{Additional Studies}

To illustrate the general character of this concept for the capture of polar volatile organic compounds, we have carried out preliminary experiments with the best two MOFs (MIL-140B and UiO-66-2CF ) for the adsorption of acetaldehyde, another pollutant that raises serious health concerns.(37) Noteworthy, these results validate this strategy to design MOFs for the capture of traces of polar VOCs in the presence of water (Figure S35) because both $\mathrm{MIL}-140 \mathrm{~B}$ and $\mathrm{UiO}-66-2 \mathrm{CF}_{3}$ are also much more efficient for the capture of acetaldehyde than the benchmark carbon material. First preliminary experiments of thermal regeneration indicate that this method can be applied to recover the adsorption capacity of $\mathrm{UiO}-66-2 \mathrm{CF}_{3}$ (Figure $\mathrm{S} 36$ and discussion in $\mathrm{SI}$ ).

\section{Conclusions}

As a conclusion, we have unveiled, through a joint experimentalcomputational strategy, a list of robust MOF adsorbents capable of capturing polar VOCs in the presence of moisture, as illustrated here with the capture of acetic acid under conditions relevant for art and cultural heritage protection. From the list of tested materials, $\mathrm{UiO}-66-2 \mathrm{CF}_{3}$ is the most promising one. We have emphasized that a hydrophobic character of the sorbent is required although not sufficient. If an optimal capture of acetic acid is targeted, one shall also rely either on the absence of polar groups in the inorganic node or on the ligand functionalization based on lipophilic but polar (e.g., perfluoro) groups to enhance the interactions with acetic acid without enhancing the affinity for water. This can be combined with the selection of an optimal pore size, together with an organic spacer enhancing vdW interactions, close to that of acetic acid to optimize its degree of confinement.

Such a strategy will certainly lead in a near future to the design of new systems for better cultural heritage preservation as well as to pave the way toward the design of new MOF sorbents for the efficient capture of polar VOCs under conditions related to domestic pollution.

\section{Acknowledgments}

M.L.P and J.P. acknowledge Fundação para a Ciência e a Tecnologia (FCT) in the scope of the Projects UID/MULTI/00612/2013 (CQB),

UID/ECI/04028/2013 (CERENA), financed by national funds through the FCT/MEC. M.L.P. is also grateful to Investigador FCT program (project IF/00993/2012/CP0172/CT0013). K.D., E.D., N.S., and C.S. also acknowledge the Investissement d'avenir Labex Patrima ANR-10-LABX-0094-01. Dr. E. 
Magnier (ILV, Versailles) is acknowledged for his assistance in the synthesis of organic linkers. G.M. thanks Institut Universitaire de France for its support.

\section{References}

1Blades, N.; Oreszczyn, T.; Bordass, B.; Cassar, M. In Guidelines on Pollution Control in Heritage Buildings; Martin, D., Ed.; The Council for Museums, Archives and Libraries: London, 2000.

2Thickett, D.; Bradley, S.; Lee, L. In Assessment of the Risks to Metal Artifacts Posed by Volatile Carbonyl Pollutants, Metal 98: Proceedings of the International Conference on Metals Conservation; Mourey, W., Robbiola, L., Eds.; James \& James: London, 1998; pp 260- 264.

3 Kontozova, V.; Deutsch, F.; Godoi, R.; Godoi, A. F.; Joos, P.; Van Grieken, R. In Characterisation of Air Pollutants in Museum Showcases, Proceedings of art2002: The 7th International Conference on Nondestructive Testing and Microanalysis for the Diagnostics and Conservation of the Cultural and Environmental Heritage; Van Grieken, R., Janssens, K., Van't dack, L., Meersman, G., Eds.; University of Antwerp: Antwerp, 2002.

4Grzywacz, C. M.; Tennent, N. H. Pollution Monitoring in Storage and Display Cabinets: Carbonyl Pollutant Levels in Relation to Artifact Deterioration. In Preventive Conservation: Practice, Theory and Research; IIC: Ottawa, 1994; pp 164- 170.

5Loupa, G.; Charpantidou, E.; Karageorgos, E.; Rapsomanikis, S. The chemistry of gaseous acids in medieval churches in Cyprus. Atmos. Environ. 2007, 41, 9018-9029, DOI: 10.1016/j.atmosenv.2007.08.035

6 Fenech, A.; Strlič, M.; Cigić, I. K.; Levart, A.; Gibson, L. T.; de Bruin, G.; Ntanos, K.; Kolar, J.; Cassar, M. Volatile aldehydes in libraries and archives. Atmos. Environ. 2010, 44, 2067-2073, DOI: 10.1016/j.atmosenv.2010.03.021

7 Krupińska, B.; Van Grieken, R.; De Wael, K. Air quality monitoring in a museum for preventive conservation: Results of a three-year study in the Plantin-Moretus Museum in Antwerp, Belgium. Microchem.

J. 2013, 110, 350- 360, DOI: 10.1016/j.microc.2013.05.006

8Prosek, T.; Taube, M.; Dubois, F.; Thierry, D. Application of automated electrical resistance sensors for measurement of corrosion rate of copper, bronze and iron in model indoor atmospheres containing short-chain volatile carboxylic acids. Corros. Sci. 2014, 87, 376-382, DOI:

10.1016/j.corsci.2014.06.047 
9 Schieweck, A.; Lohrengel, B.; Siwinski, N.; Genning, C.; Salthammer, $\mathrm{T}$. Organic and inorganic pollutants in storage rooms of the Lower Saxony State Museum Hanover, Germany. Atmos.

Environ. 2005, 39, 6098-6108, DOI: 10.1016/j.atmosenv.2005.06.047

10 Schieweck, A.; Salthammer, T. Indoor air quality in passive-type museum showcases. J. Cult. Heritage 2011, 12, 205-213, DOI: 10.1016/j.culher.2010.09.005

11Tétreault, J.; Sirois, J.; Stamatopoulou, E. Studies of lead corrosion in acetic acid environments. Stud. Conserv. 1998, 43, 17-32, DOI: 10.1179/sic.1998.43.1.17

12Brokerhof, A. W.; van Bommel, M. In Deterioration of Calcareous Materials by Acetic Acid Vapour: A Model Study, Preprints of the 11th Triennial Meeting of the ICOM Committee for Conservation; Bridgland, J., Ed.; ICOM: Edinburgh, 1996; pp 769- 775.

13Gibson, L. T.; Watt, C. M. Acetic and formic acids emitted from wood samples and their effect on selected materials in museum environments. Corros. Sci. 2010, 52, 172-178, DOI: 10.1016/j.corsci.2009.08.054

14Godoi, A. F. L.; Van Vaeck, L.; Van Grieken, R. Use of solid-phase microextraction for the detection of acetic acid by ion-trap gas chromatography-mass spectrometry and application to indoor levels in museums. J. Chromatogr. A 2005, 1067, 331-336, DOI:

10.1016/j.chroma.2004.12.054

15Gibson, L. T.; Cooksey, B. G.; Littlejohn, D.; Tennent, N. H. A diffusion tube sampler for the determination of acetic acid and formic acid vapours in museum cabinets. Anal. Chim. Acta 1997, 341, 11-19, DOI: 10.1016/S00032670(96)00567-3

16American Society of Heating Refrigeration and Air Conditioning Engineers. Museums, Libraries, and Archives. In Heating, Ventilating, and AirConditioning: Applications; ASHRAE: Atlanta, 2003; Chapter 21.

17Cruz, A. J.; Pires, J.; Carvalho, A. P.; de Carvalho, M. B. Comparison of adsorbent materials for acetic acid removal in showcases. J. Cult. Heritage 2008, 9, 244-252, DOI: 10.1016/j.culher.2008.03.001

18Cruz, A. J.; Pires, J.; Carvalho, A. P.; De Carvalho, M. B. Adsorption of acetic acid by activated carbons, zeolites, and other adsorbent materials related with the preventive conservation of lead objects in museum 
showcases. J. Chem. Eng. Data 2004, 49, 725-731, DOI: $10.1021 / \mathrm{je} 034273 \mathrm{w}$

19Dąbrowski, A. Adsorption - from theory to practice. Adv. Colloid Interface Sci. 2001, 93, 135- 224, DOI: 10.1016/S0001-8686(00)00082-8

20 Pavlogeorgatos, G. Environmental parameters in museums. Build. Environ. 2003, 38, 1457-1462, DOI: 10.1016/S0360-1323(03)00113-6

21Pinto, M. L.; Pires, J.; Carvalho, A.; de Carvalho, M. B. Assessment of Hydrophobic-Hydrophilic Properties of Microporous Materials from Water Adsorption Isotherms. Adsorption 2003, 9, 303-309, DOI:

10.1023/A:1026219813234

22Zhou, H.-C.; Kitagawa, S. Metal-Organic Frameworks (MOFs). Chem. Soc. Rev. 2014, 43, 5415- 5418, DOI: 10.1039/C4CS90059F

23 Maurin, G.; Serre, C.; Cooper, A.; Férey, G. The new age of MOFs and of their porous-related solids. Chem. Soc. Rev. 2017, 46, 3104-3107, DOI: 10.1039/C7CS90049J

24 Zhou, H.-C.; Long, J. R.; Yaghi, O. M. Introduction to Metal-Organic Frameworks. Chem. Rev. 2012, 112, 673-1268, DOI: 10.1021/cr300014x

25 Cadiau, A.; Belmabkhout, Y.; Adil, K.; Bhatt, P. M.; Pillai, R. S.; Shkurenko, A.; Martineau-Corcos, C.; Maurin, G.; Eddaoudi, M. Hydrolytically stable fluorinated metal-organic frameworks for energy-efficient dehydration. Science 2017, 356, 731- 735, DOI: 10.1126/science.aam8310

26 Van de Voorde, B.; Borges, D. D.; Vermoortele, F.; Wouters, R.; Bozbiyik, B.; Denayer, J.; Taulelle, F.; Martineau, C.; Serre, C.; Maurin, G.; De Vos, D. Isolation of Renewable Phenolics by Adsorption on Ultrastable Hydrophobic MIL-140 Metal-Organic Frameworks. ChemSusChem 2015, 8, 3159-3166, DOI:

10.1002/cssc.201500281

27Chanut, N.; Bourrelly, S.; Kuchta, B.; Serre, C.; Chang, J. S.; Wright, P. A.; Llewellyn, P. L. Screening the Effect of Water Vapour on Gas Adsorption Performance: Application to $\mathrm{CO}_{2}$ Capture from Flue Gas in Metal-Organic Frameworks. ChemSusChem 2017, 10, 1543-1553, DOI: $10.1002 /$ cssc. 201601816

28 Agostoni, V.; Chalati, T.; Horcajada, P.; Willaime, H.; Anand, R.; Semiramoth, N.; Baati, T.; Hall, S.; Maurin, G.; Chacun, H.; Bouchemal, K.; Martineau, C.; Taulelle, F.; Couvreur, P.; Rogez-Kreuz, C.; Clayette, P.; Monti, S.; Serre, C.; Gref, R. Towards an Improved anti-HIV Activity of 
NRTI via Metal-Organic Frameworks Nanoparticles. Adv. Healthc. Mater. 2013, 2, 1630- 1637, DOI: 10.1002/adhm.201200454

29Dias, E. M.; Petit, C. Towards the use of metal-organic frameworks for water reuse: a review of the recent advances in the field of organic pollutants removal and degradation and the next steps in the field. J. Mater. Chem. A 2015, 3, 22484-22506, DOI: 10.1039/C5TA05440K

30Hasan, Z.; Jhung, S. H. Removal of hazardous organics from water using metal-organic frameworks (MOFs): Plausible mechanisms for selective adsorptions. J. Hazard. Mater. 2015, 283, 329-339, DOI: 10.1016/j.jhazmat.2014.09.046

31 Hwang, Y. K.; Hong, D.-Y.; Chang, J.-S.; Jhung, S. H.; Seo, Y.-K.; Kim, J.; Vimont, A.; Daturi, M.; Serre, C.; Férey, G. Amine grafting on coordinatively unsaturated metal centers of MOFs: consequences for catalysis and metal encapsulation. Angew. Chem., Int. Ed. 2008, 47, 4144-4148, DOI: 10.1002/anie.200705998

32 Dietzel, P. D. C.; Johnsen, R. E.; Fjellvåg, H.; Bordiga, S.; Groppo, E.; Chavan, S.; Blom, R. Adsorption properties and structure of $\mathrm{CO}_{2}$ adsorbed on open coordination sites of metal-organic framework $\mathrm{Ni2}(\mathrm{dhtp})$ from gas adsorption, IR spectroscopy and X-ray diffraction. Chem. Commun. 2008, 2, 5125-5127, DOI: 10.1039/b810574j

33McDonald, T. M.; Mason, J. A.; Kong, X.; Bloch, E. D.; Gygi, D.; Dani, A.; Crocellà, V.; Giordanino, F.; Odoh, S. O.; Drisdell, W. S.; Vlaisavljevich, B.; Dzubak, A. L.; Poloni, R.; Schnell, S. K.; Planas, N.; Lee, K.; Pascal, T.; Wan, L. F.; Prendergast, D.; Neaton, J. B.; Smit, B.; Kortright, J. B.; Laura, G.; Silvia, B.; Reimer, J. A.; Long, J. R. Cooperative insertion of $\mathrm{CO}_{2}$ in diamine-appended metal-organic frameworks. Nature 2015, 519, 303-308, DOI: 10.1038/nature14327

34 Rouquérol, F.; Rouquérol, J.; Sing, K. Adsorption by Powders and Porous Solids; Academic Press: San Diego, 1999.

35 Guillerm, V.; Ragon, F.; Dan-Hardi, M.; Devic, T.; Vishnuvarthan, M.; Campo, B.; Vimont, A.; Clet, G.; Yang, Q.; Maurin, G.; Férey, G.; Vittadini, A.; Gross, S.; Serre, C. A Series of Isoreticular, Highly Stable, Porous Zirconium Oxide Based Metal-Organic Frameworks. Angew. Chem., Int. Ed. 2012, 51, 9267-9271, DOI: 10.1002/anie.201204806

36 Park, K. S.; Ni, Z.; Cote, A. P.; Choi, J. Y.; Huang, R.; Uribe-Romo, F. J.; Chae, H. K.; O'Keeffe, M.; Yaghi, O. M. Exceptional chemical and thermal stability of zeolitic imidazolate frameworks. Proc. Natl. Acad.

Sci. 2006, 103, 10186-10191, DOI: 10.1073/pnas.0602439103 
37 National Institute for Occupational Safety and Health. NIOSH Pocket Guide to Chemical Hazards, 3rd ed.; Barsan, M. E., Ed.; U.S. Department of Health and Human Services, Public Health Service, Centers for Disease Control and Prevention, 2007. 